\title{
THE IMPACTS OF INDOOR PLANTS ON PARTICIPANTS' PERCEPTUAL EVALUATIONS
}

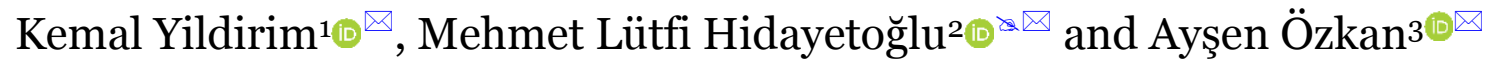 \\ ${ }^{1}$ Prof. Dr., Department of Woodworking Industrial Engineering, Gazi University, Turkey \\ ${ }^{2}$ Prof. Dr., Department of Industrial Design, Selcuk University, Turkey \\ 3Assoc. Prof. Dr., Department of Interior Architecture and Environmental Design, Hacettepe University, Turkey
}

\author{
Research Article \\ PII: S238315532000005-9 \\ Received: 19 Nov. 2020 \\ Revised: $\quad$ O5 Dec. 2020 \\ Published: 15 Dec. 2020
}

Corresponding author:

Prof. Dr., Mehmet Lütfi Hidayetoğlu,

E-mail: mlhidayetoglu@selcuk.edu.tr

\begin{abstract}
In this research, it was aimed to define the impacts of plants on the perceptual evaluation of participants in a restaurant environment. As an experimental setting, two different digital images of the modelled restaurant were used. Semantic differentiation scale was used to evaluate the environmental factors for this research environment, and the results obtained from 335 participants were evaluated with the SPSS program. The results showed that the atmospheric attributes of the restaurant with using plants had a more positive impact on the perceptual evaluations of the participants than the restaurant without plants. In addition, male and young (26-35) participants perceive more positively than female and middle-aged (36-55) participants. The use of indoor plants in key retail stores such as restaurants can increase preferability and positively impact customers' perceptual evaluations, feelings, and thoughts within first impressions.
\end{abstract}

KEYWORDS: Indoor plants, Restaurant, Customer, Perceptual evaluations, Design.

\section{INTRODUCTION}

The present-day living conditions have moved people away from the natural environment and locked them inside buildings. As a result, people spend a significant part of their lives away from the natural environment in artificial environments without plants. But, a number of researches [1-3] indicate that for humans, continuous interaction with plants as part of the natural environment has very positive impacts.

In this case, it is seen that apart from the positive impacts of using plants indoors on human psychology, plants can also be used to cleanse the air contaminated with volatile organic substances such as phenolic compounds, organochlorines and formaldehyde [1, 4-6]. For example, using plants in interiors with different action requirements, such as office environments $[7,8]$, school environments [912] and restaurant environments [3] reduced stress and distraction, and also increased positivity and pleasure.

Recently, the various potential effects of plants on humans have been the subject of many studies [3, 13-15]. A recent study reported that the strongest effects of plants on human perceptions are relief from physical discomfort following an increase in positive emotions and a decrease in negative emotions [15]. In a recent study, it has been suggested that different green coverage rates and their distance from plants have different effects on people's perception [10]. Another study showed that plants in closed environments increase positive perceptions by examining the potential of daylightfree spaces becoming livable spaces by using plants and artificial landscapes [13]. In addition, plants, which are the ambient elements in restaurants, have been reported to increase the perception of service quality and improve satisfaction and loyalty [16]. Flowering plants for office employees showed that viewing them would be a promising therapeutic approach for improving psychological relaxation and enhancing physiological functions [12]. The literature has shown that vertical gardens, green wall designs and green interior landscapes in stores can have positive impacts on customers' shopping attitudes [17]. Arguing that using green plants, especially in complex retail environments has stressreducing and pleasurable effects on customers. It was emphasized that retail spaces designed with natural elements encouraged customers' approach behaviors into consumption settings and improved their moods [18]. The effects of greenery used in retail stores on customer experiences revealed that greenery used inside and outside of the store has positive effects on customers' behavior and psychology [19]. It was stated that the plants used in retail stores increase the shopping decisions and 
satisfaction of the customers [3]. Some studies have reported that the use of plants in shopping malls has many positive effects on customer behavior [20]. It has been reported that a significant component of the design concepts, such as plants, gardens, and walkways in a retail environment, has positive effects on customer behavior in living centers [21].

There are not enough studies analyzing the impacts of plants on perceptual evaluation of humans. No comparative study has been conducted to examine the effects of indoor spaces arranged with or without plants on perceptual evaluations depending on customer characteristics. This study examines the impacts of using plants on the perceptual evaluation of customers in restaurants. The increased awareness of interior design on the perceptual evaluations of different customer groups and integration of environmental considerations into restaurants seems to be a crucial issue for interiors and designers. Most environmental effects can be effectively increased by addressing them at the design process. Plants could have a significant role in customer satisfaction. As a result, the design stages of interiors have become a crucial issue for making environmentally-friendly spaces.

The results show that the use of plants in retail environments has a positive effect on the perceptual evaluation of customers. The first hypothesis of this research is given below:

H1. The atmospheric attributes of restaurant in which plants are used or not used can positively / negatively affect the perceptual evaluations of the participants.

Previous studies show that the atmospheric attributes (ambient and design elements) of a retail store have positive impacts on customers' perceptual evaluations [22-25]. Few studies have addressed the differences between customers' perceptual evaluations in retail stores according to gender and age variables [23-26]. In this part of the study, the effects of the atmospheric environment of restaurants on customers' perceptual evaluations according to gender and age variables will be examined.

Some recent research has focused on the relationships between the atmospheric attributes of the retail store and customer behavior, and reported that there are differences between customers' preferences according to their gender [3, 24, 25]. Gender differences are seen as an important approach in the development of behavioral differences. The differences in abilities and personality features of male and female mostly reflect traditional gender roles in societies. In these studies, it was found that female's satisfaction decisions were greatly affected by their first negative emotions, while male's satisfaction decisions were due to their first positive emotions. The second hypothesis used in this research is given below:

H2. The participants' gender has a significant impact on perceptual evaluations of the restaurants.

Few studies have examined the effect of age differences on the perceptual evaluation of the atmospheric attributes of the restaurant. Psychological aging was generally discussed in these studies. Two of these studies have examined the impact of age differences on the perception of retail environments [3, 24, 25]. In a previous study, they reported that age differences due to store image have significant effects on customers' choice of stores and shopping decisions. These studies, which examine the impact of age differences on the environmental factors of the retail stores, show that age differences significantly affect the perception of the atmospheric attributes of the retail store. The third hypothesis used in this research is given below:

H3. The age of the participants has a significant impact on perceptual evaluations of the restaurants.

The methods applied to test these three hypotheses given above are discussed below.

\section{METHODOLOGY}

\section{Participants}

Research participants were randomly selected from customers using a central shopping mall in Ankara. Participants were shown two different digital images of restaurant, modelled with and without plants, on the photo paper. Before starting the research, the research survey was introduced to the participants and then they were asked to fill in the survey according to the digital images of the restaurant. The research data were collected through face-to-face interviews over a four-week period in 2018. Participants completed each survey in about fifteen minutes. A total of 335 people participated in the study, 12 of them were excluded from the evaluation due to incomplete and incorrect filling of the survey. Of the 323 people participating in the research, $48.3 \%$ were women, $51.7 \%$ were men and $50.9 \%$ were between the ages of $26-35$.

\section{Research survey and procedure}

The research survey consists of two main parts: In the first part, there are characteristics such as age and gender of the participants. In the second part, 
there is a semantic differentiation scale that determines perceptual evaluations of participants regarding restaurant environment. The participants then evaluated the significance of bipolar adjective pairs on a 1-7 semantic differentiation scale where $1=$ beautiful (positive) and $7=$ ugly (negative). A total of ten adjective pairs were evaluated by the participants: beautiful / ugly, roomy / cramped, peaceful / unpeaceful, warm / cool, good lighting / poor lighting, inviting / uninviting, pleasant / unpleasant, comfortable / uncomfortable, tidy / untidy, uncrowded / crowded. Previously, Hidayetoglu et al. [27] and Yildirim et al. [23, 24] used different forms of this scale.

The data of this research were obtained from the perceptual evaluations of the participants regarding two different digital images of restaurant modelled with and without plants (Figure 1). In many previous spatial cognitive studies, digital image [3, 23, 25, 26], and Virtual Reality (VR) technology [27-30] have been used.

\section{Environment of research}

The digital images of the Casablanca Restaurant were used as the research environment. Brown and cream colored stones are used in this restaurant' walls and columns. Wicker rope is used on the ceiling of the restaurant and herringbone wood walnut parquet is used on the floor. Climber and winder plants were used in the vertical divider wire cages of the restaurant and the wire ropes on the ceiling, and various indoor plants were used in wooden pots.

The surfaces of the armchairs, tables, coffee tables and chairs made of walnut wood in the restaurant are covered with light color varnish. Some seats have green and brown leather (Figure 1).

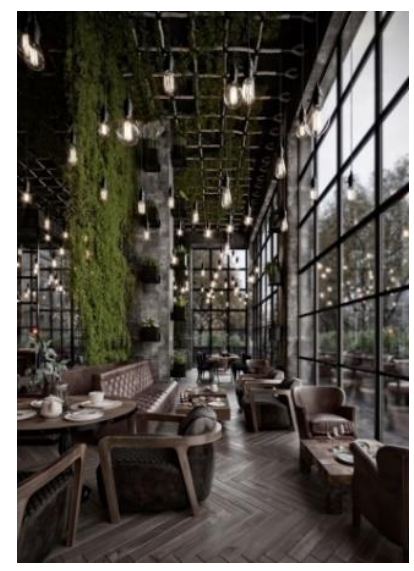

Restaurant with plant use

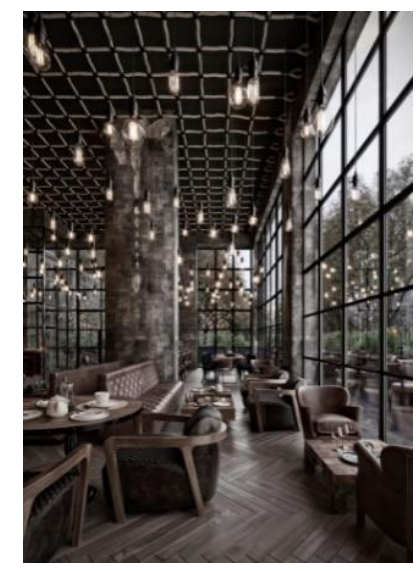

Restaurant without plant use
Figure 1. Digital images of the restaurant studied.

\section{Data collection}

Participants' evaluations of the atmospheric attributes of the restaurant were accepted as dependent variables (Tables 1, 2, 3 and 4), while restaurants with and without plants, gender and age of the participants were accepted as independent variables. Reliability tests of the obtained research data were performed with Cronbach alpha, and then the mean and standard deviation values of the data were calculated (Table 1). Afterwards, one-way analysis of variance (ANOVA) was conducted to examine the impact of differences in plant use, gender and age variables on the perceptual evaluation of restaurants. Then, the research data are graphed to compare the differences between independent variables.

\section{RESULTS AND DISCUSSION}

The results obtained from two digital images of the restaurants with and without plants, which are used as research environments, are systematically given below. First, the reliability values of the data obtained to determine the impacts of plants on the perceptual evaluations of the participants were tested with Cronbach alpha (Table 1). The reliability coefficient of the ten items used to measure the perceptual evaluations of the participants was calculated as 0.941. In previous studies [31], it was reported that the alpha reliability coefficient could only be above 0.70 for all items forming the scale. The Cronbach alpha coefficients of the data obtained from this research are well above this value. In this case, the data obtained can be considered reliable.

Table 1. Reliability values of adjective pairs used in the research

\begin{tabular}{lcc}
\hline Adjective Pairs & $\begin{array}{c}\text { Items } \\
\text { Reliability }\end{array}$ & $\begin{array}{c}\text { Scale } \\
\text { Reliability }\end{array}$ \\
\hline Beautiful / Ugly & 0.933 & \\
\hline Roomy / Cramped & 0.931 & \\
\hline Peaceful / Unpeaceful & 0.931 & \\
\hline Warm / Cool & 0.935 & \\
\hline Good lighting / Poor lighting & 0.938 & \multirow{2}{*}{0.941} \\
\hline Inviting / Uninviting & 0.932 & \\
\hline Pleasant / Unpleasant & 0.932 & \\
\hline Comfortable / Uncomfortable & 0.935 & \\
\hline Tidy / Untidy & 0.936 & \\
\hline Uncrowded / Crowded & 0.946 & \\
\hline
\end{tabular}

The differences between the participants' evaluations regarding the atmospheric attributes of the restaurant, which was arranged with or without plants, were analyzed using statistical methods. The mean and standard deviation values of the data 
obtained from the analyzes and the results of the ANOVA test are given in Table 2.

According to Table 2, statistically important differences were found between the participants' perceptual evaluations of the restaurant with and without plants at the $\mathrm{p}<0.001$ level. As a result, the participants perceived the atmospheric attributes of the restaurant with plants more positively than the restaurant without plants. According to the results of the ANOVA test, the differences between the dependent variables including the perception of the atmospheric attributes of the restaurant were found to be statistically important at $\mathrm{p}<0.001$ for the following adjective pairs: beautiful / ugly (sig.= o.oo1), roomy / cramped (sig. $=0.001)$, peaceful / unpeaceful (sig. $=0.001)$, warm / cool $(\operatorname{sig} .=0.001)$, good lighting / poor lighting (sig.= o.oo1), inviting / uninviting (sig. $=0.001$ ), pleasant / unpleasant (sig. $=$ o.oo1), comfortable / uncomfortable (sig. $=$ o.oo1), tidy / untidy (sig. $=$ o.oo1) and uncrowded / crowded (sig. $=0.001)$. The graphic representation of these results is given in Graph 1.

Table 2. Statistical results obtained from the restaurant with and without plants

\begin{tabular}{|c|c|c|c|c|c|c|c|}
\hline \multirow{2}{*}{ Adjective Pairs } & \multicolumn{2}{|c|}{$\begin{array}{l}\text { Restaurants with } \\
\text { Plants Use }\end{array}$} & \multicolumn{2}{|c|}{$\begin{array}{l}\text { Restaurants without } \\
\text { Plants Use }\end{array}$} & \multirow[t]{2}{*}{$\mathbf{F}$} & \multirow[t]{2}{*}{ df } & \multirow[t]{2}{*}{ Sig. } \\
\hline & $\mathbf{M}$ & SD & $\mathbf{M}$ & SD & & & \\
\hline Beautiful / Ugly & $2.3^{\mathrm{a}}$ & 1.60 & 3.90 & 1.65 & 144.341 & 1 & $0.001^{*}$ \\
\hline Roomy / Cramped & 2.43 & 1.54 & 4.04 & 1.68 & 162.978 & 1 & $0.001^{*}$ \\
\hline Peaceful / Unpeaceful & 2.35 & 1.60 & 4.06 & 1.58 & 185.569 & 1 & $0.001^{*}$ \\
\hline Warm / Cool & 3.00 & 1.57 & 4.63 & 1.70 & 160.958 & 1 & $0.001^{*}$ \\
\hline Good lighting / Poor lighting & 3.23 & 1.60 & 4.31 & 1.82 & 63.689 & 1 & $0.001^{*}$ \\
\hline Inviting / Uninviting & 2.46 & 1.65 & 4.14 & 1.71 & 161.082 & 1 & $0.001^{*}$ \\
\hline Pleasant / Unpleasant & 2.44 & 1.63 & 4.04 & 1.66 & 150.886 & 1 & $0.001^{*}$ \\
\hline Comfortable / Uncomfortable & 2.80 & 1.61 & 4.34 & 1.78 & 133.224 & 1 & $0.001^{*}$ \\
\hline Tidy / Untidy & 2.33 & 1.53 & 3.74 & 1.76 & 117.776 & 1 & $0.001^{*}$ \\
\hline Uncrowded / Crowded & 2.40 & 1.78 & $3 \cdot 33$ & 1.62 & 47.337 & 1 & $0.001^{*}$ \\
\hline
\end{tabular}

M: Mean values, SD: Standard deviations, F: F values, df: Degree of freedom. ${ }^{*} \mathrm{p}<0.001$ level is significant. a: Variable means ranged from 1 to 7 , with higher numbers representing more negative responses.

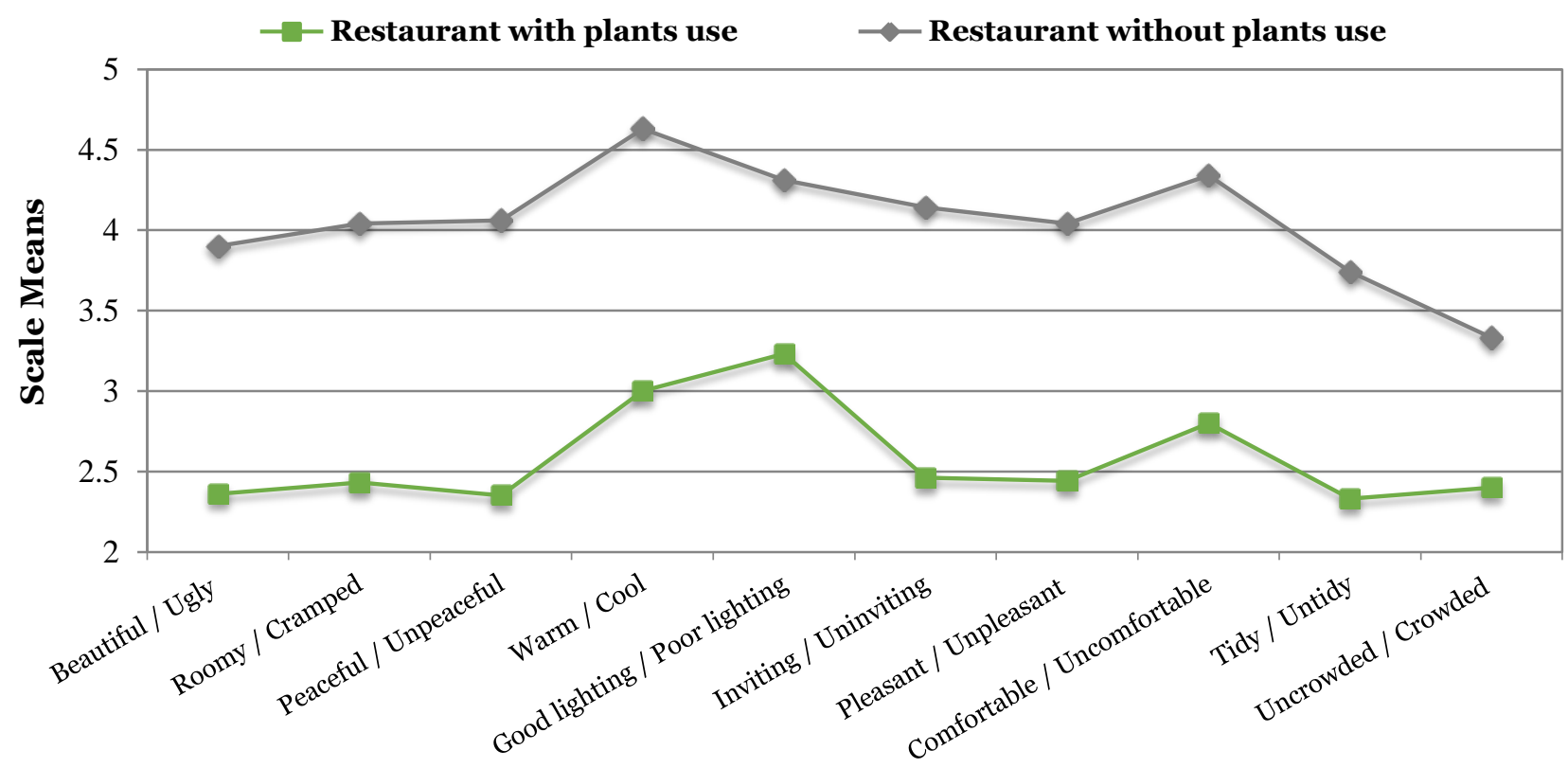

Graph 1. Impacts of restaurants with and without plants on adjective pairs. Variable means ranged from 1 to 7 , with higher numbers representing more negative responses. 
The impacts of the restaurant with plants on the perceptual evaluation of the participants can be seen in Graph 1. Accordingly, it can be said that the atmospheric attributes of restaurants with and without plants have important impacts on the perceptual evaluation of the participants. This result supported the first hypothesis (H1) used in this research. This result is consistent with the results of previous studies by Yildirim [1], Tifferet and VilnaiYavetz [13], Yildirim [17], Brengman et al. [18], Joye et al. [19], Rosenbaum at al. [20], and Ayalp et al. [32]. Differences between the perceptual evaluations of the restaurants' atmospheric attributes according to the gender of the participants (male and female) were determined. Statistical results obtained from the analysis according to the gender of the participants are given in Table 3 .

In Table 3 , it is seen that there are significant differences between the perceptual evaluations of the participants according to their gender (male and female) regarding the atmospheric attributes of the restaurants. Accordingly, it is seen that male perceive the atmospheric attributes of restaurants more positively than female. According to the results of the ANOVA test, the differences between the dependent variables including the perception of the atmospheric attributes of the restaurant according to the gender of the participants were found to be statistically important at the $\mathrm{p}<0.05 / \mathrm{p}<0.10$ level for the following adjective pairs: roomy / cramped $($ sig. $=0.003)$, peaceful / unpeaceful (sig.= 0.001$)$, warm / cool (sig. $=$ o.oo1), good lighting / poor lighting (sig.= o.oo1), inviting / uninviting (sig.= o.048), pleasant / unpleasant (sig.= 0.027), comfortable / uncomfortable (sig.= 0.011 ), tidy / untidy (sig. $=0.025$ ) and uncrowded / crowded (sig.= o.057). However, no significant difference was found at $\mathrm{p}<0.05$ level for the adjective pair beautiful / ugly. The graphical expressions of these results are given in Graph 2.

Table 3. Perceptual evaluation results according to the gender of the respondents

\begin{tabular}{|c|c|c|c|c|c|c|c|}
\hline \multirow{2}{*}{\begin{tabular}{|ll} 
Adjective Pairs & Gender \\
\end{tabular}} & \multicolumn{2}{|c|}{ Female } & \multicolumn{2}{|c|}{ Male } & \multirow{2}{*}{$\mathbf{F}$} & \multirow{2}{*}{ df } & \multirow{2}{*}{ Sig. } \\
\hline & $\mathrm{M}$ & $\mathrm{SD}$ & $\mathrm{M}$ & SD & & & \\
\hline Beautiful / Ugly & $3.22^{\mathrm{a}}$ & 1.83 & 3.05 & 1.77 & 1.351 & 1 & $0.245^{\text {is }}$ \\
\hline Roomy / Cramped & 3.45 & 1.82 & 3.04 & 1.76 & 8.771 & 1 & $0.003^{*}$ \\
\hline Peaceful / Unpeaceful & 3.45 & 1.86 & 2.99 & 1.71 & 10.778 & 1 & $0.001^{*}$ \\
\hline Warm / Cool & 4.05 & 1.81 & 3.59 & 1.82 & 10.401 & 1 & $0.001^{*}$ \\
\hline Good lighting / Poor lighting & 4.01 & 1.78 & 3.54 & 1.78 & 11.221 & 1 & $0.001^{*}$ \\
\hline Inviting / Uninviting & 3.45 & 1.88 & 3.16 & 1.87 & 3.919 & 1 & $0.048^{*}$ \\
\hline Pleasant / Unpleasant & 3.41 & 1.82 & 3.09 & 1.83 & 4.927 & 1 & $0.027^{*}$ \\
\hline Comfortable / Uncomfortable & 3.76 & 1.89 & $3 \cdot 39$ & 1.82 & 6.556 & 1 & $0.011^{*}$ \\
\hline Tidy / Untidy & 3.20 & 1.77 & 2.88 & 1.81 & 5.037 & 1 & $0.025^{*}$ \\
\hline Uncrowded / Crowded & 2.99 & 1.79 & 2,73 & 1.72 & 3.642 & 1 & $0.057^{* * *}$ \\
\hline
\end{tabular}

M: Mean values, SD: Standard deviations, F: F values, df: Degree of freedom. ${ }^{*} \mathrm{p}<0.05$ and ${ }^{* *} \mathrm{p}<0.10$ levels are significant. is: Insignificant. a: Variable means ranged from 1 to 7 , with higher numbers representing more negative responses.

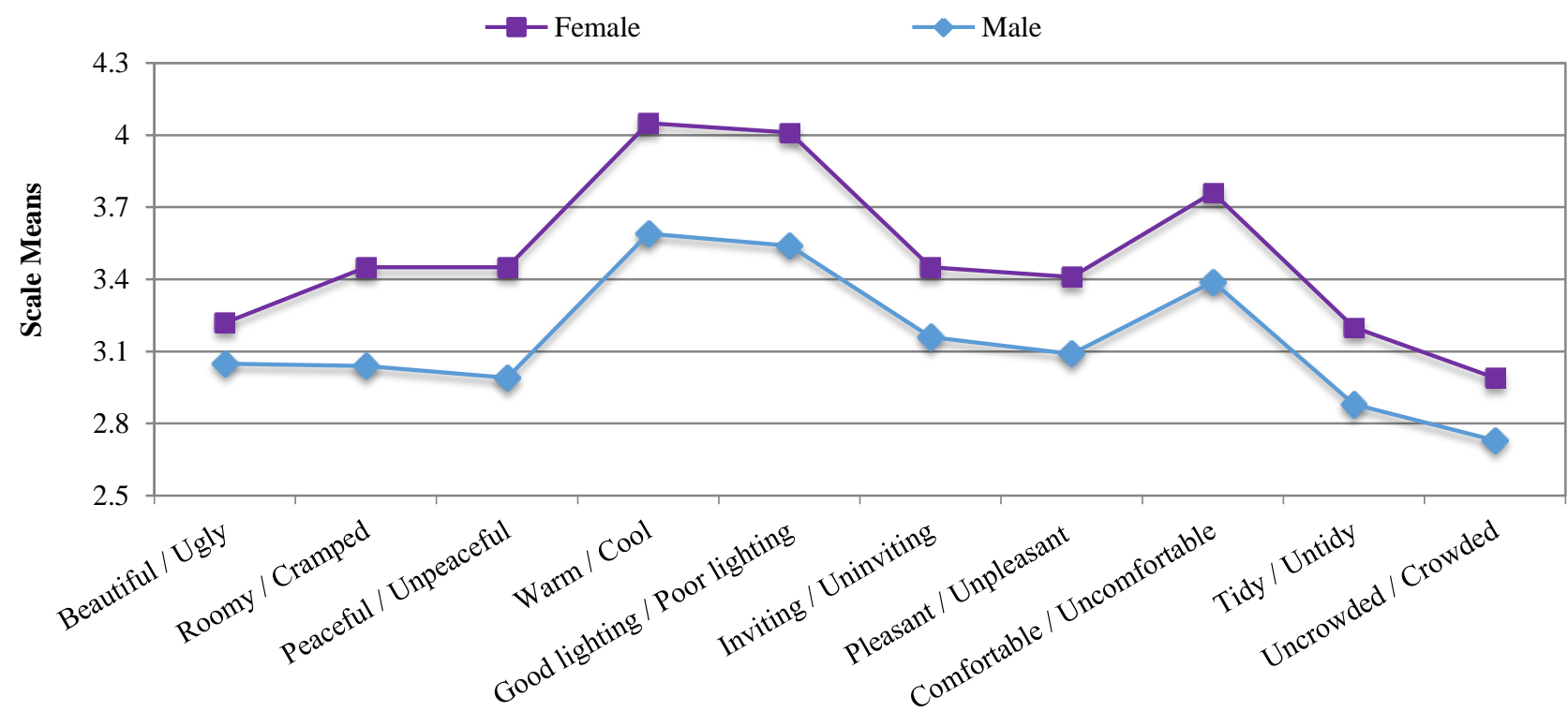

Graph 2. The effect of respondents' gender on adjective pairs. Variable means ranged from 1 to 7 , with higher numbers representing more negative responses. 
As seen in Graph 2, male participants have the lowest positive values for all adjective pairs. These findings support the second hypothesis (H2) of the research. Female have a more negative attitude than male in their perceptual evaluation of restaurants. These results are consistent with the results of previous studies conducted by Ayalp et al. [25, 32] and Yildirim et al. [3, 23, 24].

Differences between the perceptual evaluations of the restaurants' atmospheric attributes according to the age of the participants (26-35 and 36-55) were determined. Statistical results obtained from the analysis according to the ages of the participants are given in Table 4. In Table 4, it is seen that there are significant differences between the perceptual evaluations of the participants according to their age (26-35 and 36-55) regarding the atmospheric attributes of the restaurants. Accordingly, it is seen that the participants aged $26-35$ perceive the atmospheric attributes of the restaurants more positively than the participants aged 36-55.
According to the results of the ANOVA test, the differences between the dependent variables including the perception of the atmospheric attributes of the restaurant according to the age of the participants were found to be statistically important at the $\mathrm{p}<0.05, \mathrm{p}<0.10$ level for the following adjective pairs: warm / cool (sig. $=0.009)$, good lighting / poor lighting (sig.=o.oo5), pleasant / unpleasant $($ sig. $=0.08)$, comfortable / uncomfortable (sig. $=0.005$ ) and uncrowded / crowded $(s i g .=0.030)$. Graphic explanations of the research results are given in Graph 3. As seen in Graph 3, younger participants (26-35) have the lowest values (positive values) for all adjective pairs. These findings support the third hypothesis $\left(\mathrm{H}_{3}\right)$ of the research. Middle-aged participants (36-55) have a more negative attitude than younger participants (26-35) in their perceptual evaluation of restaurants. These results are consistent with the results of previous studies conducted by Yildirim, et al. [3, 24] and Ayalp et al. [25].

Table 4. Perceptual evaluation results according to the age of the respondents

\begin{tabular}{|c|c|c|c|c|c|c|c|}
\hline \multirow{2}{*}{ Adjective Pairs } & \multicolumn{2}{|c|}{ 26-35 } & \multicolumn{2}{|c|}{ 36-55 } & \multirow{2}{*}{$\mathbf{F}$} & \multirow{2}{*}{ df } & \multirow{2}{*}{ Sig. } \\
\hline & $\mathrm{M}$ & SD & $\mathrm{M}$ & SD & & & \\
\hline Beautiful / Ugly & $3.04^{\mathrm{a}}$ & 1.71 & 3.22 & 1.93 & 1.569 & 1 & $0.211^{\text {is }}$ \\
\hline Roomy / Cramped & 3.18 & 1.77 & 3.29 & 1.84 & 0.597 & 1 & $0.440^{\text {is }}$ \\
\hline Peaceful / Unpeaceful & 3.14 & 1.77 & 3.27 & 1.83 & 0.846 & 1 & $0.358^{\text {is }}$ \\
\hline Warm / Cool & 3.63 & 1.78 & 4.01 & 1.86 & 6.871 & 1 & $0.009^{*}$ \\
\hline Good lighting / Poor lighting & 3.57 & 1.73 & 3.97 & 1.84 & 8.052 & 1 & $0.005^{*}$ \\
\hline Inviting / Uninviting & 3.20 & 1.85 & 3.40 & 1.91 & 1.800 & 1 & $0.180^{\text {is }}$ \\
\hline Pleasant / Unpleasant & 3.12 & 1.78 & 3.37 & 1.87 & 3.077 & 1 & $0.080^{* *}$ \\
\hline Comfortable / Uncomfortable & 3.37 & 1.89 & 3.78 & 1.81 & 7.939 & 1 & $0.005^{*}$ \\
\hline Tidy / Untidy & 2.95 & 1.75 & 3.12 & 1.83 & 1.373 & 1 & $0.242^{\text {is }}$ \\
\hline Uncrowded / Crowded & 2.71 & 1.79 & 3.01 & 1.72 & 4.751 & 1 & $0.030^{*}$ \\
\hline
\end{tabular}

M: Mean values, SD: Standard deviations, F: F-values, df: Degree of freedom. ${ }^{*} \mathrm{p}<0.05$ and ${ }^{* *} \mathrm{p}<0.10$ levels are significant. is: Insignificant. a Variable means ranged from 1 to 7 , with higher numbers representing more negative responses.

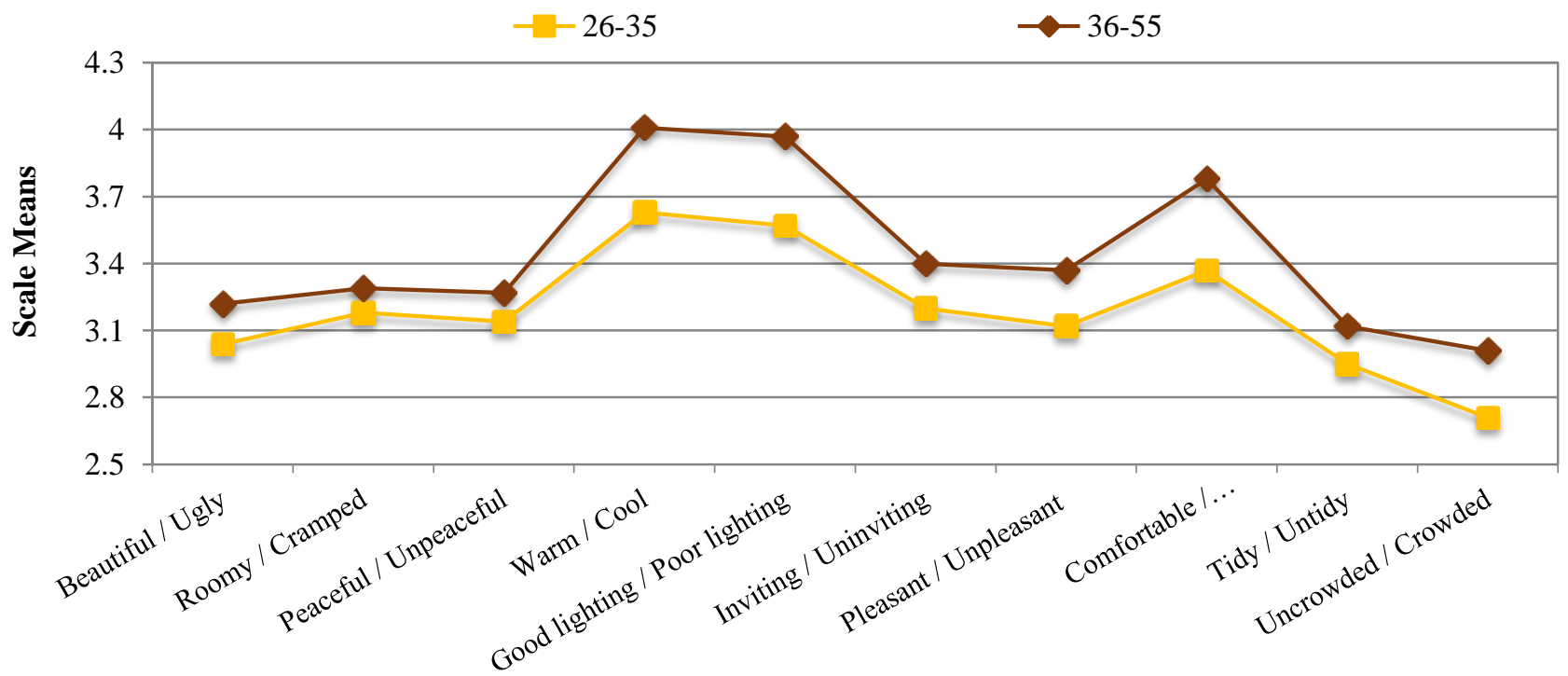

Graph 3. The effect of respondents' age on adjective pairs. Variable means ranged from 1 to 7 , with higher numbers representing more negative responses 


\section{CONCLUSION AND SUGGESTIONS}

In this research, it was tried to determine the impacts of the plants used in restaurants on the perceptual evaluations of the participants. For this purpose, the results obtained from this research are given below, respectively.

According to the preliminary results, statistically important differences were found between the participants' perceptual evaluations of the restaurant with and without plants at the $\mathrm{p}<0.001$ level. As a result, the participants perceived the atmospheric attributes of the restaurant with plants more positively than the restaurant without plants. The use of plants (potted plants, algae wall panels and plant, etc.) in key retail stores such as restaurants can positively impact customers' perceptual evaluations, feelings and thoughts.

This situation is attributed to the primary preference of all elements that evoke nature and nature. This view has been discussed in many studies before. It is clarified in many studies that plants make strong nature connotations for humans [3]. In conclusion, this study showed that plant use in restaurants affects customers' feelings as more peaceful, calm, warm, and pleasant. Also been proven to evoke a relaxed feel among customers.

In the retail sector, space design is crucial and a key factor as a marketing strategy in order to attract customers' attention and increase sales potential by spending more time. In this sense, the results of this study showed that the restaurant where plants are used perceived as more inviting and comfortable. In addition, it has been observed that restaurants with green plants are perceived as more tidy, roomy and less complex.

The other important result of this research was the gender differences according to evaluations of the atmospheric attributes of the restaurant with or without plants. Female took a more negative approach than the male about the atmospheric attributes of the restaurant. This result supports the findings that female's satisfaction decisions are greatly affected by their first negative feelings. Yildirim et al. [24] suggested that female spend more time in retail stores than male [3, 23-25]. These results show that female have a more detailed and critical approach to their shopping behaviour.

In another result, it is seen that there are important differences between the perceptual evaluations of the participants between the ages of 26-35 and 36-55 regarding the atmospheric attributes of the restaurant. It was found that the participants aged 26-35 perceived more positively atmospheric attributes of the restaurant than the participants aged 36-55. This result regarding age supports the results obtained by Ayalp et al. [25] and Yildirim et al. [3, 24]. The research results shared above show that retailers and designers can easily influence customers' perceptual evaluations by using plants in restaurants.

\section{Limitations and further research}

As a continuation of the previous study this research is based on the perceptual evaluation of the restaurant's atmospheric attributes by potential customers. Within this scope, the first impressions of the potential customers in the perception of the restaurant were evaluated. Digital photographs were used in this study and shopping malls were chosen as the easiest transportation network to apply the survey to potential customers. In the next study, perceptual evaluations of customers who currently use a restaurant determined in a real space environment can be investigated. A research environment can be created by making periodic changes in the space. Rather than the first impression of the customers in the existing space, discussion can be established on whether it will become inviting and attractive for their next arrival.

In the future studies, the positive effects of plants can be tested in various retail and service stores with different functions such as apparel, supermarket, hypermarket or hairdresser.

\section{DECLARATIONS}

\section{Acknowledgements}

We would like to thank the Company of Zebrano Furniture for allowing this research environment, Ferdi Olmuş who contributed to the implementation of the surveys, and the respondents who completed the survey.

\section{Authors' Contributions}

All authors contributed equally to this work.

\section{Competing interests}

The authors declare that there is no competing interests.

\section{REFERENCES}

[1] Yildirim K (2013). Bitkilerin iç mekân kirleticileri üzerindeki etkileri (Effects of plants on indoor pollutants), İçmimar Dergisi. 28: 107-115. Google Scholar

[2] Rogers K (2019). Added information on the health benefits of spending time in nature. Biophilia hypothesis, 
https://www.britannica.com/science/biophiliahypothesis. (accessed 23 October 2020).

[3] Yildirim K, Kaya N N, Olmus F (2020). The effects of indoor plants on customers' shopping decisions in a restaurant environment. International Journal of Retail \& Distribution Management, 48(12): 13011314. https://doi.org/10.1108/IJRDM-02-20200053

[4] Cinar H, Ozturk Y, Yildirim K (2018). Effects of Surface Veneering, Edge Banding, and Drilling Holes for Handles and Hinges of Wood-Based Boards on Formaldehyde Emission. Forest Product Journal, 68(3), 264-271. https://doi.org/10.13073/FPJ-D-1800025

[5] Aydogan A, Cerone R (2020). Review of the effects of plants on indoor environments. Indoor Built and Environment. In press. https://doi.org/10.1177/1420326X19900213

[6] Han K T (2019). Effects of Indoor Plants on the Physical Environment with Respect to Distance and Green Coverage Ratio. Sustainability, 11: 3679.

[7] Smith A J, Fsadni A, Holt GD (2017). Indoor living plants' effects on an office environment. Facilities, 35(9/10): 525-542. https://doi.org/10.1108/F-092016-0088

[8] Genjo K, Matsumoto H, Ogata N, Nakano T (2019). Feasibility study on mental health-care effects of plant installations in office spaces. Japan Architectural Review, 2(3): 376-388. https://doi.org/10.1002/2475-8876.12098

[9] Li D, Sullivan W C (2016). Impact of views to school landscapes on recovery from stress and mental fatigue. Landscape \& Urban Planning, 148: 149-158. https://doi.org/10.1016/j.landurbplan.2015.12.015

[10] Han K T (2020). Effects of visible greenness, quantity and distance of indoor plants on human perceptions and physical parameters. Indoor and Built Environment, In press. https://doi.org/10.1177/1420326X20939595

[11] Han K T (2018). Influence of passive versus active interaction with indoor plants on the restoration, behaviour and knowledge of students at a junior high school in Taiwan. Indoor and Built Environment, 27(6): https://doi.org/10.1177/1420326X17691328

[12] Elsadek M, Liu B (2020). Effects of viewing flowering plants on employees' wellbeing in an office-like environment. Indoor and Built Environment, In press. https://doi.org/10.1177/1420326X20942572

[13] Tifferet S, Vilnai-Yavetz I (2017). Phytophilia and service atmospherics: The effect of indoor plants on consumers. Environment \& Behavior, 49(7): 814844. https://doi.org/10.1177/0013916516669390

[14] Kim J, Koo Cha SH, Koo C, Tang S (2018). The effects of indoor plants and artificial windows in an underground environment. Building and Environment, 138: 53-62. https://doi.org/10.1016/j.buildenv.2018.04.029

[15] Han K T, Ruan L W (2019). Effects of indoor plants on self-reported perceptions: a systemic review. Sustainability, 11: 4506. https://doi.org/10.3390/su11164506
[16] Apaolaza V, Hartmann P, Fernández-Robin C, Yáñez $D$ (2020). Natural plants in hospitality servicescapes: The role of perceived aesthetic value. International Journal of Contemporary Hospitality Management, 32(2): 665-682. https://doi.org/10.1108/IJCHM-032019-0240

[17] Yildirim NN (2018). The effects of living walls on users at the commercial interiors. Journal of Strategic and International Studies, 13(1): 95-105.

[18] Brengman M, Willems K, Joye Y (2012). The impact of in-store greenery on customers. Psychology \& Marketing, 29(11): 807-821. https://doi.org/10.1002/mar.20566

[19] Joye Y, Willems K, Brengman M, Wolf K (2010). The effects of urban retail greenery on consumer experience: Reviewing the evidence from a restorative perspective. Urban Forestry \& Urban Greening, 9(1): 57-64. https://doi.org/10.1016/j.ufug.2009.10.001

[20] Rosenbaum M S, Otalora M L, Ramírez G C (2016). The restorative potential of shopping malls. Journal of Retailing and Consumer Services, 31: 157-165. https://doi.org/10.1016/j.jretconser.2016.02.011

[21] Rosenbaum M S, Ramirez G C, Camino J R (2018). A dose of nature and shopping: The restorative potential of biophilic lifestyle center designs. Journal of Retailing and Consumer Services, 40: 66-73. https://doi.org/10.1016/j.jretconser.2017.08.018

[22] Skandrani H, Mouelh, N B D, Malek F (2011). Effect of store atmospherics on employees' reactions. International Journal of Retail \& Distribution Management, $\quad 39(1)$ 51-67. https://doi.org/10.1108/09590551111104477

[23] Yildirim K, Ayalp N, Aktas G G, Hidayetoglu M L (2014). Consumer perceptions and functional evaluations of cash desk types in the clothing retail context. International Journal of Retail \& Distribution Management, 42(6): 542-552. https://doi.org/10.1108/IJRDM-03-2013-0056

[24] Yildirim K, Cagatay K, Hidayetoglu M L (2015). The effect of age, gender and education level on customer evaluations of retail furniture store atmospheric attributes. International Journal of Retail \& Distribution Management, 43(8): 712-726. https://doi.org/10.1108/IJRDM-01-2013-0034

[25] Ayalp N, Yildirim K, Bozdayi M, Cagatay K (2016). Consumers' evaluations of fitting rooms in retail clothing stores. International Journal of Retail \& Distribution Management, 44(5): 524-539. https://doi.org/10.1108/IJRDM-06-2015-0085

[26] Yildirim K, Hidayetoglu M L, Capanoglu A (2011). Effects of interior colors on mood and preference: Comparisons of two living rooms. Perceptual \& Motor Skills, 112(2): 509-524. https://doi.org/10.2466/24.27.PMS.112.2.509-524

[27] Hidayetoglu M L, Yildirim K, Akalin A (2012). The effects of color and light on indoor wayfinding and the evaluation of the perceived environment. Journal of Environmental Psychology, 32(1): 50-58. https://doi.org/10.1016/i.jenvp.2011.09.001

[28] Wolbers T, Hegarty M (2010). What determines our navigational abilities? Trends in Cognitive Sciences, 
14(3):

https://doi.org/10.1016/j.tics.2010.01.001

[29] Wallet G, Sauzéon H, Larrue F, N'Kaoua B (2013). Virtual/real transfer in a large-scale environment: Impact of active navigation as a function of the viewpoint displacement effect and recall tasks. Advances in Human-Computer Interaction, 2013: 879563. https://doi.org/10.1155/2013/879563

[30] Hwang J, Yoon S Y, Bendle L Y (2012). Desired privacy and the impact of crowding on customer emotions and approach-avoidance responses:
Waiting in a virtual reality restaurant. International Journal of Contemporary Hospitality Management, 24(2): 224-250. https://doi.org/10.1108/09596111211206150

[31] Panayides P (2013). Coefficient alpha: interpret with caution. Europe's Journal of Psychology, 9(4): 687696. https://doi.org/10.5964/ejop.vgi4.653

[32] Ayalp N, Yildirim K, Cagatay K (2017). Effect on users of the seating element types in cafés / restaurants. Gazi University Journal of Science, 30(4): 15-28. Link, Google Scholar 